\title{
Toilet Box
}

1 Material Analysis (Materials and Techniques, Provenance and Parallels)

A gold alloy object $\left(\mathrm{Z}_{4} / 96\right)$ was found in the fill of the west tunnel of T.4, near the entrance to the west room, in the dark bottom layer (Then-Obłuska 2017, Fig. 10). It is a profiled cylinder made of beaten sheet metal [Fig. 6.1]. At one end, the edge was bent outward and decorated with bosses. The top of the cylinder is embellished with a beaded ring that serves as the setting for a carnelian bead. The bead is most probably threaded onto a wire that ends in a spherical ball. Its shape and construction are the same as that of the metal knobs known from Ballana, although they differ in the type of metal used. Silver cups with convex lids surmounted by a cylindrical knob are known from Ballana tombs (Emery and Kirwan 1938, Pl. 66C-F). A carnelian bead is set on the top of one of them, B.6-11 (Emery and Kirwan 1938, 275, size $13.4 \mathrm{~cm}$ in height). Again, the above-mentioned objects were found in a prince's tomb dated to the period between $\mathrm{AD} 42 \mathrm{O}$ and 440 (Török 1986, 197).
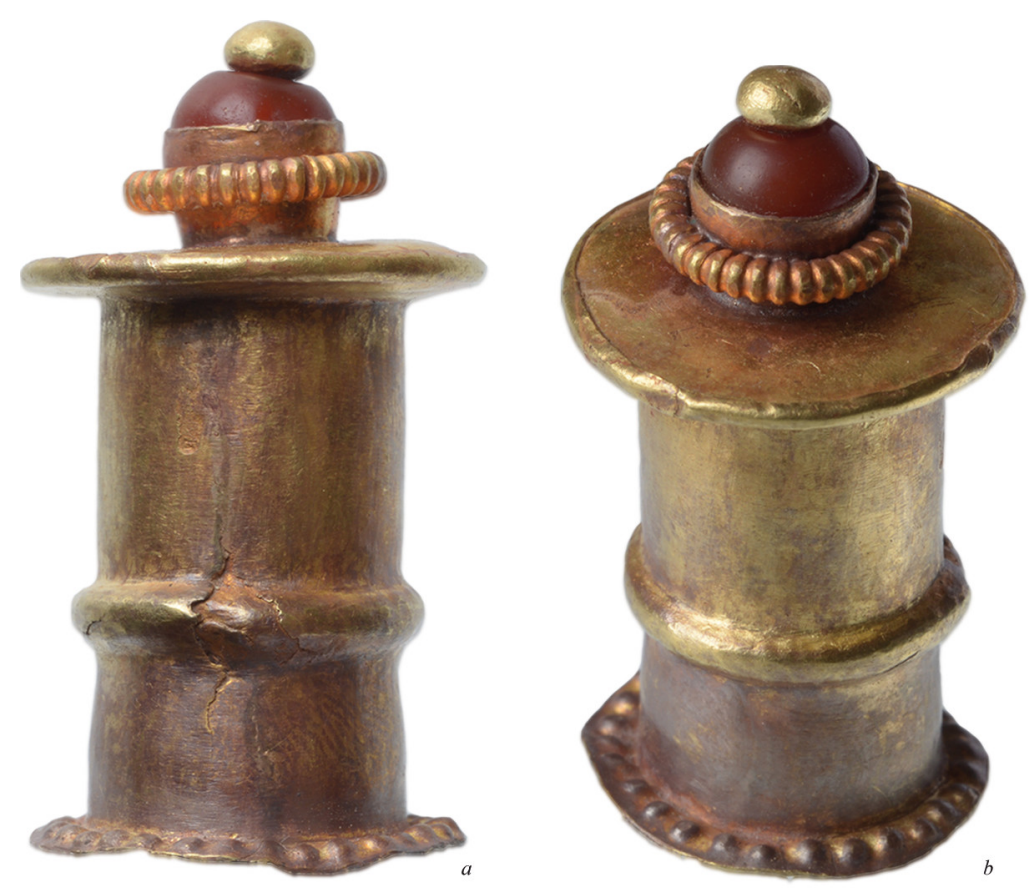

$10 \mathrm{~mm}$

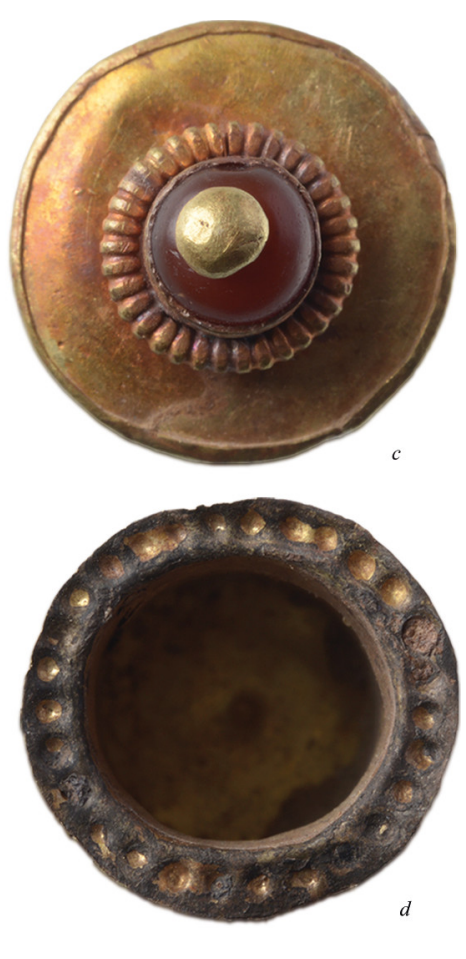

Z4/96

FIGURE 6.1 Lid knob: top, bottom and side views

PHOTOS BY A. KAMROWSKI, PLATE BY J. THEN-OBŁUSKA 